\title{
JOÃO VÊNCIO: OS SEUS AMORES - \\ CENAS DE UMA MASCULINIDADE SUBALTERNA
}

Andréa Maria Moraes ${ }^{l}$

RESUMO: O objeto deste trabalho é o estudo da relação entre a masculinidade, o amor, como um de seus atributos, e o poder, no romance João Vêncio: os seus amores, de Luandino Vieira.

ABSTRACT: This article analyses the interplay of masculinity with love and power in the novel JoãoVêncio: os seus amores, by Luandino Vieira

PALAVRAS-CHAVE: Colonialismo; Cênero; Identidade; Masculinidade; Nacionalidade

KEYWORDS: Colonialism; Gender; Identity; Masculinity; Nationality

\section{SOBRE GÊNERO}

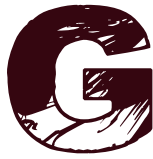

ênero, segundo Teresa de Lauretis (1984, p. 208), não é uma pro-

priedade dos corpos - embora Bordieu² diga que ele se inscreve nos corpos - nem algo existente a priori nos seres humanos, mas, nas palavras de Foucault (apud LAURETIS, 1984, p. 208), trata-se de um conjunto de efeitos produzidos em corpos, comportamentos e relações sociais, por meio de uma "complexa tecnologia política".

Dentro de cada cultura há um sistema de significações que relaciona o sexo a conteúdos culturais, de acordo com valores e hierarquias sociais, ligadas à organização da desigualdade social.

1 Mestranda do Programa de Estudos Comparados de Literaturas de Língua Portuguesa (FFLCH-USP).

2 "(...) a definição social dos órgãos sexuais, longe de ser um simples registro de propriedades naturais, diretamente expostas à percepção, é produto de uma construção efetuada à custa de uma série de escolhas orientadas, ou melhor, através da acentuação de certas diferenças, ou do obscurecimento de certas semelhanças." (BOURDIEU, 2010, p. 23). 
Joan Kelly (apud LAURETIS, p. 216) afirma que em qualquer das formas históricas tomadas pela sociedade (feudal, capitalista, socialista), um sistema de sexo-gênero e um sistema de relações produtivas operam simultaneamente para reproduzir estruturas socioeconômicas e o domínio masculino da ordem social.

De acordo com Lauretis (1984, p. 225), o poder é o que motiva não necessariamente de modo consciente ou racional - os "investimentos" feitos pelas pessoas em posições gênero-discursivas. Outras importantes dimensões da diferença social, como classe, raça e idade, cruzam o gênero para favorecer ou desfavorecer certas posições.

A sexualidade, normalmente considerada como uma questão natural, particular e íntima, é, na visão de Foucault (apud LAURETIS, p. 220), de fato, construída na cultura, de acordo com objetivos políticos da classe dominante. Dito dessa forma, parece não existir liberdade de escolha identitária fora do discurso que circula, por meio de prescrições ou interdições, nos espaços de socialização do sujeito. Cabe a este, no entanto, a questão de reconhecer-se e fazer a sua construção identitária a partir daquela na qual já nasce inserido por meio do discurso, em um processo denominado agência. No processo de agência ou agenciamento, o sujeito sustenta, critica, adere, rejeita, integra, afasta, obedece ou resiste às regras impostas pela cultura, definidas como normas, comportamentos e papéis que não são necessariamente aquilo que ele almeja para si enquanto traço identitário.

\section{SOBRE MASCULINIDADE}

Podemos entender masculinidade como aquilo que torna um homem verdadeiramente homem - senso de honra, virilidade etc. - aos olhos de outrem e de seus próprios olhos, dentro de uma determinada cultura e, principalmente, dentro de um momento histórico nessa cultura.

De acordo com Bourdieu (2010, p. 61), trata-se a masculinidade de um investimento em "jogos sociais", tal como um "princípio indiscutido de todos os deveres" de um homem "para consigo mesmo", 
"o motor ou móvel de tudo que um homem se deve", "aquilo que deve cumprir para estar agindo corretamente consigo mesmo", para permanecer digno, a seus próprios olhos, segundo "uma certa ideia de homem".

É possível distinguir, dentro de uma mesma cultura, mais de um padrão de masculinidade, que podem variar segundo o tempo, o espaço, a classe social, o grau de instrução e outros fatores, tais como raça e idade. Essas masculinidades convivem e se interpenetram, influenciando umas às outras e, não raro, estabelecendo hierarquias entre elas. É mesmo possível falar em masculinidade hegemônica, embora este seja um conceito problemático, não se podendo dizer que exista uma essencialidade em ser hegemonicamente masculino.

No dizer de Connell e Messerschimdt (2013, p. 208), a masculinidade hegemônica pode ser entendida como um padrão de práticas (coisas feitas e não apenas uma série de expectativas de papéis ou uma identidade) de modo a assegurar a dominação, seja de um gênero sobre outro, ou mesmo de um padrão sobre outro dentro de um mesmo gênero, no sentido de um modelo hegemônico masculino exercer poder sobre modelos subordinados.

Hegemonia, aqui, deve ser tomada no sentido gramsciano do termo (ABOIM, 2008, p. 274), isto é, caracteriza-se como uma liderança cultural-ideológica de uma classe social sobre as outras, embora possa se referir também à coerção ou dominação de um grupo social sobre outro.

Importante lembrar que as identidades de gênero constroem-se em relação umas com as outras. Hegemonia não quer dizer violência, embora possa ser sustentada pela força, mas significa uma ascendência alcançada por meio da cultura, das instituições (família, Estado, escola, religião) e da persuasão (mídia e outras máquinas de propaganda).

A masculinidade hegemônica também não quer dizer uma maioria estatística. É provável que apenas uma minoria entre os homens a adote, mas ela é um padrão normativo, que incorpora "a forma mais honrada de ser de um homem" (CONNELL E MESSERSCHMIDT, 2013, p. 245). Ela 
exige que todos os outros homens se posicionem em relação a ela e legitima ideologicamente a subordinação global sobre o mesmo gênero (outros homens) e outros gêneros (mulheres e gays).

Para efeito deste trabalho, em que se analisa uma personagem masculina de um texto escrito na Angola colonial (1968), João Vêncio: os seus amores, de Luandino Vieira, estudaremos uma forma de masculinidade dominante, heterossexual, branca, patriarcal, racista, em cotejo com uma masculinidade subordinada, híbrida, situada no entrecruzamento de culturas - portuguesa e africana -, que flerta com uma ruptura da ordem colonial, mas acaba por confirmá-la.

João Vêncio, mulato, pobre, semiletrado, vive um conflito identitário em um universo governado por homens brancos, heterossexuais, que comandam não só os aparelhos de Estado, a escola, as instituições religiosas, mas pretendem comandar também as relações interpessoais, criminalizando e patologizando todo comportamento desviante à ordem heteronormativa, branca, homofóbica e racista.

Collier (apud CONNELL e MESSERSCHIMDT, p. 255) observa ainda que a hegemonia de um padrão nem sempre é negativa; possui vantagens e pode atender a interesses e desejos dos grupos subalternos, do contrário não conseguiria se afirmar como hegemônica. É importante destacar que hegemonia nem sempre se confunde com dominação.

Interessa-nos discutir neste ensaio a instabilidade de um regime de identificação por gênero, a masculinidade, numa faceta que é um de seus atributos, a do amante.

João Vêncio vive nos escombros - que caracterizam a pós-modernidade - das heranças do amor-paixão, do amor romântico, da tradição do pensamento libertino. Ele está preso numa cela por tentativa de assassinato de uma de suas mulheres. Na cadeia, narra a um interlocutor os descaminhos e desvãos de suas experiências amorosas, que ele entende terem concorrido para sua sorte atual. Em seu relato, podemos distinguir que ele é presa do amor-paixão, entendido como aquele que celebra a ausência do outro; noção de amor que 
penetrou no ocidente pela via do romantismo; é um amor que parte do desejo em direção à morte.

De acordo com Rougemont (2003, p. 329), nós, os ocidentais, somos todos tributários, inconscientemente, de um conjunto de hábitos e costumes amorosos cujos símbolos foram criados pela mística do amor cortês, segundo a qual paixão significa sofrimento, que pode chegar até a morte pelo objeto amado. Rougemont também assinala que, por influência dos ideais de cavalaria, parece haver uma relação muito estreita entre amor e guerra, ou entre o instinto combativo e o instinto sexual, ou ainda uma "cumplicidade fisiológica" entre os instintos de combate e de procriação.

É possível observar isso no tipo de linguagem adotada (ROUGEMONT, p. 331) para se referir ao amor, que utiliza inúmeras metáforas de guerra desde a antiguidade, tais como "a mulher se rende ao homem que a conquista por considerá-lo o melhor guerreiro"; o deus do amor é um arqueiro que dispara "flechas mortais"; "o amante faz o cerco à dama; trava assaltos amorosos à sua virtude; ele ataca frontalmente a dama; persegue-a; procura vencer suas defesas e rompê-las de surpresa, até que ela capitula".

Mas aí acontece uma inversão na lógica do conquistador: ele se tornará vassalo dessa suserana, segundo a norma das guerras feudais, como se fosse ele quem tivesse sofrido a derrota. Nesse ponto, o homem troca de lugar com a mulher, ele se transforma em um não-homem, feminiza-se.

A versão contemporânea dessa inversão pode ser encontrada em Fragmentos de um discurso amoroso, de Roland Barthes (1981, p. 27), no verbete "Ausência": "Todo homem que fala a ausência do outro, feminino se declara: esse homem que espera e sofre, está milagrosamente feminizado. Um homem não é feminizado por ser invertido sexualmente, mas por estar apaixonado".

Assim, nada resta a este guerreiro subjugado senão dar provas de sua valentia. E como fazê-lo? No caso de João Vêncio, é preciso lançar mão da tradição do pensamento libertino para melhor compreender: 
Rougemont (2003, p. 453) explica que, segundo Pierre Klossowski, para Sade, o mal é o único elemento da Natureza. E ele justifica o desejo sádico de libertar-se das tiranias sensuais pelo excesso de depravação. Glosando outra afirmativa de Sade sobre a Criação, segundo a qual "o princípio da vida, em todos os seres, é o mesmo da morte; nós recebemos e alimentamos dentro de nós os dois ao mesmo tempo", Klossowski (apud ROUGEMONT, p. 331) opõe essa opinião de Sade à de Freud, que vê uma antítese entre o instinto de morte e Eros. Para Rougemont essa antítese é puramente aparente. Assim, "se a vida e a Natureza criada não são senão perfídias e crueldade, então, é necessário, para nos libertarmos delas, que nos excedamos em crueldades e perfídias". Só há duas alternativas: exercer a crueldade contra si mesmo ou contra o próximo. Sade escolheu o próximo: prefere ser criminoso a ser vítima. De modo que a consciência sádica é o oposto da consciência romântica. $O$ romantismo se penitencia para conservar o objeto amado, enquanto Sade quer matá-lo.

Outro aspecto que merece atenção nas práticas amorosas de João Vêncio é o uso da agressividade. Esse comportamento viola outro preceito amoroso do amor cortês que é, segundo Rougemont (2003, p. 333), a necessidade social de dar um estilo ao amor, uma aspiração suprema da sociedade medieval no plano ético. E ela se torna mais imperiosa na medida em que os hábitos se tornam mais ferozes. "É preciso elevar o amor à altura de um rito, pois a violência transbordante da paixão o exige. Se as emoções não se deixam enquadrar em formas e regras, a barbárie será inevitável".

A nossa hipótese é a de que João Vêncio, apaixonado, feminiza-se e, para reafirmar sua integridade como homem, leva sua masculinidade ao paroxismo, assumindo poder de vida e de morte sobre seus objetos amorosos.

O regime colonial, bárbaro em sua essência, parece não deixar alternativas à nossa personagem que, apesar de um tanto insubmisso à ordem preconizada, busca se afirmar pela sexualidade e pela violência, mirando-se nos modelos de masculinidade hegemônica colo- 
cados em circulação pelo discurso colonial, sem, contudo, reconhecer-se completamente neles.

\section{IMAGENS MASCULINAS}

Albert Memmi (1967, p. 86) afirma que a colonização fabrica colonizados como fabrica colonizadores. Arriscaríamos dizer que ela fabrica também masculinidades e suas antípodas.

Segundo Darcy Ribeiro, em 8 de janeiro de 1454 o papa Nicolau V estabelecia as normas básicas da ação dos colonizadores, falando da

plena e livre faculdade, entre outras, de invadir, conquistar, subjugar a quaisquer sarracenos e pagãos, inimigos de Cristo, suas terras e bens, a todos reduzir à servidão e tudo praticar em utilidade própria e dos seus descendentes. Tudo declaramos pertencer de direito in perpetuum aos mesmos $D$. Afonso e seus sucessores, e ao infante. (apud LACERDA, 2010, p. 67, grifos do autor)

Tais pronunciamentos serviram como guia e autorização para todo tipo de atrocidades praticadas pelas nações católicas europeias em suas colônias, legitimando o uso da violência.

Numa outra fase do regime colonial português, nas décadas de 3040 do século $X X$, a máquina de propaganda salazarista cria o mito de Portugal como nação imperial, com vocação histórico-providencial para colonizar e evangelizar. O ato colonial de 1930 (ROSAS, 2001, p. 1034), no seu artigo $2^{\circ}$, dizia: "É da essência orgânica da Nação Portuguesa desempenhar a função histórica de possuir e colonizar domínios ultramarinos e de civilizar populações indígenas".

O salazarismo enaltece o mito da essência católica da identidade nacional, entendendo a religião católica como elemento constitutivo do ser português, como atributo definidor da própria nacionalidade e da sua história. A religião é considerada uma necessidade de Estado. 
Carneiro Pacheco (apud ROSAS, p. 1036), Ministro da Educação Nacional durante o Estado Novo, em seu discurso de recepção ao pessoal do ensino primário dizia: "Muito pior do que a treva do analfabetismo num coração puro é a instrução materialista e pagã, que asfixia as meIhores inclinações".

Por fim, o Estado salazarista moldou a figura do "homem novo", espelho de conduta para cidadãos portugueses e colonos, que deveriam ser capazes de interpretar e cumprir a "alma e o destino ontológico da nação",

um ser temente a Deus, respeitador da ordem estabelecida e das hierarquias sociais e políticas como decorrências do organismo natural e imutável das sociedades, pronto a servir à pátria e o império, cumpridor dos seus deveres na família e no trabalho, destituído de "ambições doentias" e "antinaturais" e satisfeito com a sua honrada modéstia (ROSAS, 2016 p. 1037, grifos nossos)

Essas eram as "virtudes da raça", expressão de um referencial essencial da ruralidade, da terra regada pelo suor dos que "sobre ela labutavam, mãe da riqueza, da temperança e da ordem”. (ROSAS, 2016, p. 1037, grifos nossos).

Tratava-se de um discurso ideológico de um projeto político totalizante. O "homem novo" era alguém expurgado dos vícios do liberalismo, do racionalismo e da contaminação marxista. Era um "homem-trabalhador", "chefe de família", esforçado, respeitador, obediente, simples, ancorado no pequeno mundo da sua família e vizinhança, fiel às tradições, à "ordem natural das coisas", "mesmo quando o destino o arrancava à aldeia para o lançar no meio hostil e perigoso da fábrica e da cidade." (cf. ROSAS, 2016, p. 1046)

Eis um modelo de masculinidade que se pretende normativo, veiculado pela máquina de propaganda do colonialismo, destinado a balizar a conduta do homem branco português e a servir como referencial também ao homem das colônias, inclusive o indígena. Esse modelo nada mais é do que o modelo do conquistador retocado pelas exigên- 
cias do momento colonial. Pode-se dizer que ele atravessou décadas ou mesmo séculos, ganhando novas roupagens segundo os interesses ditados pelos diferentes etapas do processo de colonização.

Selma Pantoja (1996, p. 75), descrevendo as relações sociais e de gênero em Luanda nos primórdios da colonização, a partir de um estudo de história de Angola elaborado por Silva Correa (militar que serviu na colônia angolana), assinala que uma "miscelânea" - termo pejorativo cunhado pelo próprio autor - de cultos, coisas, gentes e ideias caracterizavam o espaço urbano de Luanda. O perímetro urbano da cidade era um território de mestiçagem, de hibridizações genéticas e simbólicas entre africanos negros e "os desgarrados de Além-Mar".

Numa época em que os luso-africanos da cidade ocupavam posições de relevo na sociedade local, descrevem-se os locais como "povo não-cristão", "negros sórdidos, feios e feras".

A autora observa que as mulheres brancas são apresentadas como cópias das mulheres europeias, sempre acompanhadas de comitivas de escravas. Em geral, suas vidas eram confinadas ao ambiente familiar, encerradas em casa, enquanto as escravas viviam em trânsito pelas ruas da cidade.

Em relação ao homem branco, dizia-se que o clima destruía a sua razão. Trazia a loucura: "o fogo da sensualidade atiçado pela ardência do clima devora a natureza humana" (PANTOJA, p. 77). Havia uma preocupação com as concubinagens de brancos com negras, referidas como "atos libertinos de europeus que têm concubinas e muitas vezes são apresentadas às próprias esposas". Já as senhoras brancas eram elogiadas pelo cumprimento dos votos conjugais.

Destaque-se que, mesmo dentro de toda a "miscelânea" do centro urbano luandense, o modelo de comportamento imposto como "civilizado' era sustentado pelo tripé trabalho-religião-família e assim permaneceu em tensão com suas antípodas, quais sejam, as atividades à margem do sistema produtivo-paganismo-formações familiares fora do casamento burguês. Os naturais da terra eram os brancos nascidos em África e os negros eram "os outros". 
É patente a ambiguidade da moral colonizadora, com sua visão religiosa cristã europeia, seu patriarcalismo, etnocentrismo, racismo e suas transgressões a esses códigos.

Nos anos 60, quando o livro João Vêncio: os seus amores foi escrito, outra imagem de "homem novo" era veiculada pelo movimento de luta pela libertação das colônias do domínio português. Tentou-se criar e estimular um perfil identitário à altura das exigências da guerra de libertação em consonância com a modernidade militar, dentro do modelo do Estado-Nação que se desejava constituir.

Em síntese, essa socialização de novo tipo tinha por finalidade demonstrar os desequilíbrios, sobretudo ao nível social, provocados pelo colonialismo. Ao mesmo tempo, ela buscava atenuar as referências tradicionais (ritos, símbolos, relações de parentesco, hierarquia linhageira) por entendê-las incompatíveis com os objetivos da guerra que se travava.

Os líderes desse movimento tentaram elaborar seletivamente as práticas e valores que deveriam inspirar esse novo perfil identitário, distinguindo-as entre as "reacionárias" e as que deviam ser "valorizadas" (CABAÇO, 2007, p. 411). Entre aquelas que deveriam ser valorizadas estavam os sistemas de produção e troca e o valor social do parentesco (que, na visão dos líderes, representariam a família, a solidariedade e a história, transigindo com a prática da poligamia e a realização dos ritos de iniciação), além da produção artística e criativa.

Ao menos numa fase pré-independência, o "homem novo" do Movimento Popular pela Libertação de Angola (MPLA) pouco conseguiu diferenciar-se dos padrões que pretendia combater: tratava-se de um homem voltado para a produção (trabalho); obediente a uma moral destinada à construção de uma nova ordem social e econômica (a moral socialista no lugar da religião católica) e devotado a uma causa (a libertação do jugo colonial, no lugar da missão civilizatória). 


\section{JOÃO VÊNCIO: OS SEUS AMORES}

Nossa personagem, João Vêncio, passa ao largo desses modelos de masculinidade normativa. Não consegue dar conta deles, mas elabora sua própria ética particular.

Nascido em um musseque, espaço à margem dos grandes centros urbanos angolanos - onde impera a exclusão social e seu corolário, isto é, a tensão entre a norma vigente e o comportamento desviante -, ele, sem qualificação profissional, encontra-se fora do sistema produtivo:

Até já tive emprego de Estado, funcionário assalariado, um ano. De farda e tudo. Ela gostava assim, era uma cafusa que eu estraguei, filha da família - eu sou escravo dos meus amores. Deixe-lhe - ela queria muitas burguesias. Eu não encho a barriga de pançudos com o suor do meu rosto. Capinar jardim, engraxar sapato, vender jornal, lotaria, servir no bar, viajar de ajudante de carro, isso eu faço - trabalho serviço que dá só a cúria. Comigo não fazem fortuna, muadié. Capiango? Nunca pus a mão em seara leia. Pode ver meu cadastro - intermediário não é ladrão, vivo de honestas comissões, róquefélo um pouco. (VIEIRA, 1987, p. 40)

Declara ter sido também cicerone de marujos, ajudando-os a contratar prostitutas. Não conheceu a mãe. Vivia sob os cuidados de uma madrasta, de quem não gostava porque o maltratava, e de seu pai, um padeiro. Diz ter frequentado todas as religiões, utilizando esse argumento para rebater a acusação que lhe fazem de "hereje". Mas confessa-se admirador de "Padre Viêra", com quem travou contato no seminário, de onde fugiu.

Da escola se refere apenas aos momentos em que foi castigado fisicamente pela professora, por escrever palavras erradas ou quando foi pego beijando um de seus amores, Mimi, de quem trataremos mais adiante. 
De seus amores, diz que cada um ocupava a ponta de uma estrela e uma quarta pessoa é colocada no centro do astro. No cotidiano do musseque, representado no livro analisado, é possível encontrar uma valorização precoce da experiência sensorial do amor.

O mais importante deles, para João Vêncio, era Tila, mulher de um vizinho "cangudo" (branco de baixa condição social), retirada de um asilo por ele, um homem mais velho. João Vêncio tinha então oito anos e Tila lhe permitia algumas intimidades físicas:

Tarde tarde e eu no colo dela aninhado e ela brincando com os meus caracóis mulatos melados (VIEIRA, p.18)

Eu ainda a procuro, eu hei de - Ihe dar encontro no paraíso infernal, preciso seja. Eu não posso morrer sem sentir outra vez seu torrume adúltero, seu pilão de mão surrando o meu amor deslegal (VIEIRA, p. 67)

Mulher-cadela, eu gostava dela. Ela é a ponta um da estrela, a toda ela. E quando me pôs na varanda colonial - ela estava só com a roupinha de fazer meninos que eu rasguei e mordi também-saquelou meu destino: "Pequeno assassino..." (VIEIRA, p. 35)

João Vêncio alimentava, contudo, uma raiva do marido de Tila porque este a maltratava:

Eu gostava de sentir o meu coraçãozinho aquecer, encher de ódio, fel doce, dentro do meu corpo, ria, babava se calhar, pensando ele, o doutoro, a espernear quando eu lhe matasse. Porque todos os dias ele surrava a desgraçada. Surrava que eu sentia os barulhos mesmo que não percebia como é ele batia e ela não chorava, não gritava, só ele é que se ouvia, começava muito baixo e depois acabava num grito a repetir: "Luz! Luz! Luz!"' (VIEIRA, p. 21) 
Uma obsessão perseguia João Vêncio: "matar o doutoro, amar com ela" (VIEIRA, p. 20). Certo dia, a espreitá-los, surpreendeu os dois durante uma dessas ocasiões, em pleno êxtase do marido de Tila e compreendeu o que se passava entre ambos. Desde então, essa imagem se gravou na sua memória e o perseguia. A imagem de um homem guinchando sobre uma mulher.

Outro de seus amores era uma menina cabo-verdiana, Máristrêla, que ele, João Vêncio, descreve como extremamente feiosa, com cara de "puco". Nessa relação é explícito o enlace entre amor e violência:

Mas todos os dias a minha alegria era encher o coração de ódio, afiar agulhas para a Màristrêla, para as nossas brincadeiras com os pássaros. (VIEIRA, p. 21)

E eu via-lhes luzir o brilho verdiano, espetando as agulhas de crochê que eu afiava. Que era nosso jogo: cegar os bichinhos para eles cantarem melhor. Verdade, muadié, kiri muene! - cegados, cafofos, canta multiplicado o bigode e o'nário-do-Kuanza. A dor purifica a beleza? Muadié, tem cada pergunta! Solte meus passarinhos, não cresça outra vez o caim rõim no meu coração remorsificado.

Furava ela, os olhos. Brilhava ela, os olhos, as agulhas, no nosso cantozinho. Cantava crioulinhos a ninar as bonecas e depois eu é que era o carrasco da rainha de Cachemir - no coração de todos os cantores, a seta de cupido, a agulha-croché.

(VIEIRA, p. 50)

João Vêncio relata que Màristrela se prostituiu aos doze anos com um comerciante branco e, a partir de então, a menina conseguia alimentar toda a família. Desse momento em diante, ele não consegue mais sequer dirigir-lhe um cumprimento.

Mas sua fixação permanecia em Tila que, segundo ele, Ihe deu Mimi, um colega de escola com quem desenvolveu uma relação íntima. O co- 
lega é descrito como frágil e de aparência andrógina. No início, o garoto era vítima de gracejos, insultos e até agressões físicas na escola. João Vêncio, seduzido pelos modos do colega, decidiu defendê-lo perante os demais. E teve aí uma relação que diz ter sido a mais feliz de sua vida: "Ele era meu, eu era o dono - e eu era o escravo trabalhador, ele o senhor (...) ele é a mais inútil beleza de minha vida." (VIEIRA, p. 37)

João Vêncio associa sua relação com Mimi a uma vingança pela rejeição que sofria de Tila e à impossibilidade de uma relação mais completa com Màristrêla:

Fizemos frente-a-frente - raivosos de não ser como marido e sua mulher, nossos pitossexos rebitados chocando-se, querendo esconder-se em cada um, cada qual. Eu acendi raivas, chorei, eu pensava a Màristrêla deitada comigo nas penas dos pássaros, só juntos e eu com ela nunca quis fazer malandro; e a menina do asilo, menina Tila, que eu queria casar e ela me tratava parecia eu era o filho das entranhas da dor dela. Desforra é, o amor macho? (VIEIRA, p. 55)

Mimi faleceu por apanhar da professora quando foi surpreendido beijando João Vêncio.

No centro de sua estrela de três pontas, onde João Vêncio situa seus três amores, Tila, Maristrêla e Mimi, ele coloca Florinha, uma de suas mais frustrantes experiências amorosas. Trata-se de uma mulher que se aproximava dos garotos do musseque promovendo mensalmente homenagens a seu filho morto e iniciando-os sexualmente:

Ela era a mãe-do-amoro: ensinava o que a gente não precisava ainda saber mas ia ser preciso. Nós éramos os amigos do filho falecido, oferecia sua riqueza uniquíssima. No princípio não aceitava comigo, era miúdo feijão. Depois eu fui a primeira vez - era depois de ver o primeiro zoológico doutor, guinchado. Bufei, denunciei: ela estava estendida na esteira, tão amarrotada, eu tive pena, lembrei minha menina do asilo que 
eu queria e vi o orangotango - macaco gritando - mergulhei. E tive raiva. A Florinha me segurou nos ombros, murmurava: "Cuetado ! Mon'a uiso hanji. Tão pequenino, pipito iala kué, monámi? Tive raivas: eu tinha oito anos, com a menina Tila eu tinha casado quase e ela me gozava? Arfei, fúrias, lembrei o macarrão, menguenei, olhos fechados. E então ela começou a chorar: (...) Ela estava sendo minha mãe, entristada da minha sabença. Tive mais raiva, gritei: “Luz!'. Eu não me lembro mais o que passou: a gente lutámos, eu lhe rasguei seus trapos, machuquei, rompi de unhas, berrava o xalado, xinguilava parecia, disseram os outros. (VIEIRA, p. 78-79)

Depois desse episódio, Florinha teve sua casa incendiada e acabou sendo deportada do musseque pela vizinhança, que a surpreendera em plena atividade com os garotos.

Exceto seus três amores e Florinha, a quem via como uma mãe, João Vêncio declara não ter amado mais ninguém. A bailunda, a muIher que tentou assassinar, foi comprada a um conhecido e a tentativa de assassinato se deu quando ela foi surpreendida em pleno adultério, praticando um ato sexual com um homem branco:

E vi o macaco-quipanzéu aos guinchos na minha bailundinha e ela a simpatizar-se na jigajoga dum jacaré de cheiro. Gritava mas eu arrumei-lhe na cama e apertei o pescoço. Muadié, mire: as mãos de um amor. Que eu quero ver sempre mulher cerrar os olhos, comigo. E ela foi cerrando, e eu gostei como ela apagou a luz da alma, eu estava também a lhe acompanhar nos musseques areais, caminho de nosso céu, as almas juntas. Eu nunca tive tanta paz." (VIEIRA, p. 47-48)

Após esse momento, a mulher foi reanimada em um hospital e João Vêncio julgado e condenado. "Sexopata, sádico, hereje, lombrosiano". Epítetos que Ihe deu a justiça colonial. 


\section{JOÃO VÊNCIO, SUBSTANTIVO MASCULINO}

É possível extrair do discurso de João Vêncio como experimenta a frustração amorosa e a inferioridade, especialmente no que se refere à sua imagem como homem. E como luta para restabelecer a paz consigo mesmo por meio de gestos violentos.

Devido à precariedade de suas posses materiais; sem uma família nuclear ao estilo patriarcal e burguês - constituída, no momento do crime, apenas por sua companheira -; sem professar solenemente uma religião, apesar de seu declarado apreço por todas elas, sem um engajamento político, não obstante reconhecer e respeitar o de seu interlocutor na cela da prisão - com quem sugere partilhar o almoço preparado pela esposa -, tendo sofrido toda sorte de abusos na infância, com um cotidiano marcado pela violência - que ia desde castigos físicos na escola até assistir pessoas com participação política em âmbito público agindo como "bestas" em âmbito privado (como é o caso da personagem de Diodato, um bolchevique que defendia "a classe operária", mas que espancava a mulher em casa) -, parece de se esperar que a tendência será buscar uma válvula de escape, procurando exercer algum tipo de poder para restaurar sua integridade, inclusive como homem.

Em um estudo sobre masculinidade em Maputo, por ocasião da promulgação da nova Lei de Família em 2003, Sofia Aboim (2008, p. 287) constata que uma das formas de (re)construir a masculinidade em tempos de mudança nas relações de gênero, sobretudo diante da dificuldade em alcançar a dominação masculina, seja por meio do controle tradicional ou do sucesso econômico, reside no poder simbóliCo3 atribuído à sexualidade masculina. Mas João Vêncio não consegue

3 Conforme Bourdieu (2010), o poder simbólico é um poder invisível que só pode ser exercido com a cumplicidade daqueles que não querem saber que lhe estão sujeitos ou mesmo que o exercem. Trata-se de um poder subordinado, isto é, de uma forma transformadora, irreconhecível, transfigurada e legitimada de outras formas de poder. Essas formas se dissimulam e passam por uma transfiguração ou eufemização garantindo uma transubstanciação das relações de força, fazendo ignorar-reconhecer a violência que elas encerram objetivamente e transformando-as, assim, em poder simbólico, capaz de produzir efeitos reais 
elaborar seu próprio enredo de homem de sucesso, nem econômico, nem no que se refere à conquista de mulheres, de modo a tornar-se invejado por outros homens ou admirado pelas mulheres.

Flagrou sua mulher em adultério, fazendo sexo com um homem branco, a quem compara a um macaco-quipanzéu. Naquele instante, vieram à tona todas as memórias das frustrações sofridas com seus amores anteriores: de Tila, que perdeu para o doutoro; de Màristrêla, que perdeu para a prostituição com um homem branco, comerciante, que passou a alimentar sua família; de Mimi, morto por uma surra da professora ao ser surpreendido beijando o próprio João Vêncio; de Florinha, que via como uma mãe, mas que o humilhou sexualmente. Quando até a sexualidade falha como uma das maneiras de recuperar a credibilidade em si como homem, entra em cena o recurso à violência.

João Vêncio ensaia uma ruptura com a ordem colonial na medida em que seu comportamento desafia as leis estabelecidas, mas acaba por entrar em cumplicidade com ela no momento em que se mostra vítima da representação masculina dominante. Ele precisa reconstruir sua imagem viril diante de outros homens, para outros homens e contra a feminilidade, já que se sente um não-homem.

Assim, seus crimes representam certa forma de "coragem", porque podem ser "reconhecidos" pelas forças da polícia, da justiça, e por seu companheiro de cela. Existe todo um sistema no aparato colonial e também nas forças que se dispõem a combatê-lo clamando por atos de exibição de bravura.

Bourdieu (2010, p.66) explica que o que chamamos de "coragem" muitas vezes tem suas raízes em uma forma de covardia: para comprová-lo, basta lembrar todas as situações em que, para lograr atos como matar, torturar ou violentar, a vontade de dominação, de exploração ou de opressão baseou-se no medo "viril" de ser excluído do mundo dos "homens" sem fraquezas, dos que são por vezes chamados de "duros" porque são duros para com o próprio sofrimento e sobretudo sem dispêndio aparente de energia. 
para com o sofrimento dos outros - assassinos, torturadores e chefetes de todas as ditaduras e de todas as "instituições totais", mesmo as mais ordinárias, como as prisões, casernas ou internatos.

A sociedade colonial luandense é a dama medieval perante a qual o nosso cavaleiro tem de provar sua valentia. E o amor às mulheres ou até a outros homens é moeda de troca perante seus pares masculinos.

João Vêncio declara “Eu amo o amor” (VIEIRA, p. 76) e se utiliza do discurso amoroso corrente para tentar construir sua própria narrativa amorosa e reafirmar sua diminuta parcela de poder, sua imagem como homem. Trata-se de uma ascese para consigo mesmo e seus pares. Existe uma mística em sua conduta; tentando mostrar que ainda tem uma família e uma posição na sociedade, uma certa respeitabilidade:

Sou pessoa de educação: mulher bonita é quipia de jogo-de-bilha? Toda mulher é uma nossa-senhora. Sou delicado, não aceito evolucionismo: o homem vem do macaco? Balelas! Eu sou de origem divinal - sô Ruas, fubeiro, não é pessoa.

Aqui eu faço o parentes. O muadié é de luzes mas arreceio. Doutoro juiz, delegado e outros maiorais de leis, eles só veem a linha recta, não sabem a porta estreita. De polícia, não admiro - eles são a res publica. Que eu ciumei o macacão chifrador, senti dor de chavelho, fervi vinganças iníquas, vejam só!? Quem não me conhece, como é quer me conhecer? Baronas são de todos, só de você se ela é que quer. Eu não gosto de ser deus de ninguém. Mas a beleza é minha, essa é minha honra - e o quipanzéu-branco defecou-lhe. Eu tinha de limpar os lençóis do coito simióide - a boniteza do mundo é meu aquário. (VIEIRA, p. 48-49)

\section{UM CONTRACANTO NOS OUVIDOS DA NAÇÃO}

Acreditamos que as obras literárias não têm sentido em si mesmas, elas derivam seus sentidos das formações discursivas em que se inscrevem, sendo, no entanto, passíveis de produzir rupturas nessas for- 
mações e, em última instância, contribuir mesmo para reconfigurar relações de poder.

João Vêncio: os seus amores arranha o cânone da Literatura de Língua Portuguesa, abrindo uma brecha para o descentramento, isto é, o deslocamento do poder do centro para a periferia, ensaiando um esfacelamento das estruturas de poder coloniais.

Na contemporaneidade, especialmente no final do século XX, Stuart Hall (2014, p. 7) observa que uma mudança estrutural está fragmentando as paisagens culturais de classe, de gênero, de sexualidade, de etnia, de raça e de nacionalidade. No passado, tais paisagens nos tinham fornecido sólidas localizações como indivíduos sociais. No presente, essas transformações estão mudando nossas identidades pessoais, abalando a ideia que temos de nós mesmos como sujeitos integrados.

Especificamente, no caso de João Vêncio: seus amores, Fonseca (1998, p. 158) vai nos dizer que Luandino Vieira coloca em circulação um discurso à revelia de uma voz autoritária que defende o controle necessário para a eficácia da ordem, onde mostra-se o avesso daquilo que se diz: é o "barulhamento ensurdecedor das contradições silenciadas pelo controle das dissidências", evidenciando outros modos de leitura das chamadas identidades nacionais. O processo identitário passa a ser lido "a partir das digressões que dificultam a produção de um único sentido". A fala individual de João Vêncio pode ser redimensionada pelo coletivo e não se agrega à visão triunfalista do discurso da nação emergente.

No dizer da autora

João Vêncio fala de amores que transitam pelas modulações de sua voz, escorregando em interditos, escorando-se provisoriamente nos sons e vozes desarticulados (...). Querendo-se inteiro, João Vêncio se anuncia outros, muitos, e é esse corpo sempre provisório que emblematiza o corpo plurissonante de sua cultura, aliás de todas as culturas, quando assumem a sua heterogeneidade. (...) A nação mostra-se no texto de Luandino Vieira no desassossego do seu próprio projeto. (FONSECA, p. 163) 


\section{REFERÊNCIAS BIBLIOGRÁFICAS}

ABOIM, Sofia. Masculinidades na encruzilhada: hegemonia, dominação e hibridismo em Maputo- Análise Social, vol. XLIII (2º), 2008, 273-295

BARTHES, Roland. Fragmentos de um discurso amoroso. $2^{\mathrm{a}}$. ed. Rio de Janeiro: Francisco Alves, 1981.

BOURDIEU, Pierre. A dominação masculina, $9^{\text {a }}$ ed., Rio de Janeiro: Bertrand Brasil, 2010.

. O Poder simbólico, $14^{\mathrm{a}}$ ed., Rio de Janeiro: Bertrand

Brasil, 2010.

BRANCO, Lúcia Castelo. João Vêncio: suas femininas alíneas amoráveis Boletim CESP, v. 13 n. 15, 106-111, jan/jun., 1993.

CABAÇO, José Luiz de Oliveira. Moçambique: identidade, colonialismo e libertação. São Paulo, 2007, FFLCH/USP.

CONNELL, Robert W. \& MESSERSCHMIDT, James W. Masculinidade hegemônica: repensando o conceito - Estudos Feministas, 21 (1): 424, janeiro-abril/2013, p. 241 a 282.

FONSECA, Maria Nazareth Soares. Imagens de Nação em Afrodições Literárias - Boletim do CESP - v. 19, $n^{\circ} 24$ - jan./jun. 1999, 155-168, PUC/MG. HALL, Stuart. A identidade cultural da pós-modernidade, $10^{\mathrm{a}}$ ed. São Paulo: Lamparina, 2014.

LACERDA, Marina Basso. Colonização dos corpos: ensaio sobre o público e o privado. Patriarcalismo, patrimonialismo, personalismo e violência contra as mulheres na formação do Brasil, PUC-Rio - certificação digital $\mathrm{n}^{\circ}$ 0812079/CA, 2010.

LAURETIS, Teresa. A tecnologia do gênero. In: HOLLANDA, Heloísa Buarque de (org.). Tendências e impasses: o feminismo como crítica da Cultura. Rio de Janeiro: Rocco, 1984.

MEMMI, Albert . Retrato do colonizado precedido pelo retrato do colonizador. Rio de Janeiro: Paz e Terra, 1967.

PANTOJA, Selma. Luanda: relações sócias e de gênero, II RIHA, 1996: 75-81 
ROSAS, Fernando. O salazarismo e o homem novo: ensaio sobre o Estado Novo e a questão do totalitarismo - Análise Social, vol. XXXV (157), 2001, p. 1031-1054.

ROUGEMONT, Denis de. A História do amor no ocidente, $2^{\mathrm{a}}$. ed. São Paulo: Ediouro, 2003.

VIEIRA, José Luandino. João Vêncio: os seus amores, $2^{\mathrm{a}}$ ed. Lisboa: Edições 70, 1987. 